\title{
苦战二年 人寿年丰
}

\section{一江西省余江夥根除血吸虫病的經驗}

\section{李 俊 九}

（中共余江县委第一曹記）

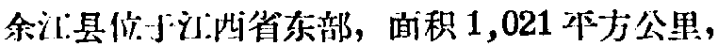

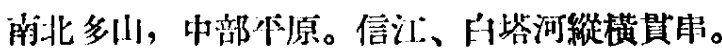

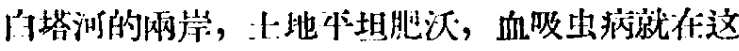

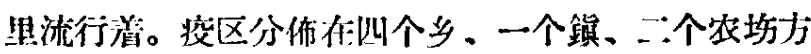
圆五十华里的汇圍队，人11 35,152 人。几作来經过 类便檢查，有血吸䖯奖的人有 4,042 人，各地粪檢阳

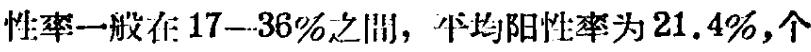

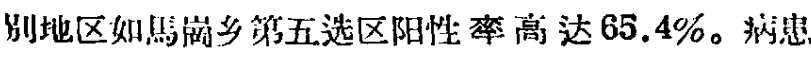
者以农民为最多，佔 74.2\%，年龄以 15-19 岁的为 最高，佔 68.9\%，20-24 岁和 10-14 岁的次之，性

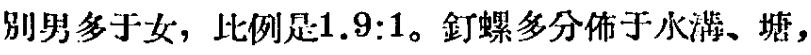
和与灌激清相通的低洼晚四，面积为 782,655 代方公 尺。釘螺密度以水灌为最高，达 264 只/本方公尺，本 均为 7.2 只/本方公尺, 水塔炏之, 最高达 14 只/作

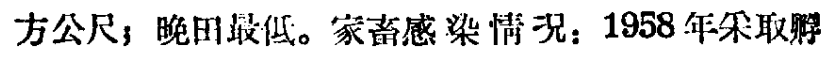
化三次, 重点結合直晹粘朕刮取的方泆, 在瘦区范圍 內进行一次检查, 在 1,235 头耕斗中, 阳性 65 头, 阳 性率为 $5.2 \%$ ，其中㣴牛感染率为 $6.8 \%$ ，水牛感染 率为 $3.7 \%$, 检查猪 170 头全部为阴性。

过去, 由于国民党反动派的長期血腥給治, 对人 民疢苦熟䅐无䐗, 以致血吸出病的荧延为害年深一 年。五十年来搉此病䉼邆生命的不下三千余人。因为 死亡的人增多, 出生率减少, 而致整个村生毁灭的的 有二十多个。如倪桂乡建头村五十作前有 500 余厅, 1,300 余人，現在只有 15 戶， 59 人，其中还有 4 户、 20 人 是在解放后从外地迁来的。得了血吸出病的人,

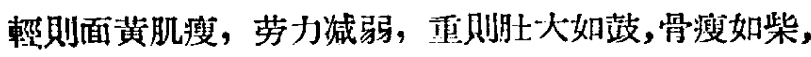
夹头劳力。他們說: “一張鋤头兩厅鉄, 拿到手里就 想歇”, “下四扶根棍, 不到师头就想眮”。劳力减少, 田园荒無，生产降低。当时弓塘乡籣田圾想流行过这 样一首歌䛾: “蘭畦坂的禾, 一亩割一籍, 高兴兩人 抬，不高兴就一人䭾”。人民生活困苦已极，他們說: “有女莫嫁楊家車，日大赶牛事，晚上紡棉花，要肉 吃，等年下，要鵎吃，抱娃炼”。山此可見血吸虫病 的危害多公重。

解放厓，党伃导着人民翷了身，也領导着这里的
人民逐步地消灭了血吸出痤, 根本败变了疫区的面 貌。弓塘乡是血吸出病严重流行的地区, 过工次脢人 多, 劳力少且弱, 住年必須付出:千多元㕍請答工, 勉虽应付一种一收，經过治将后，这个乡 1957 年劳 少不但不触, 而了目剩余了七千多个劳 11 。生产比迅速 得到了发展，1956 年增产 $18.4 \% ， 1957$ 年又垤产

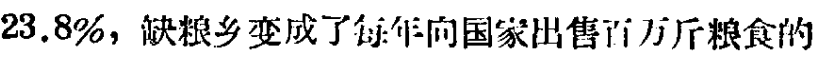

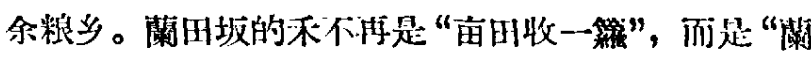

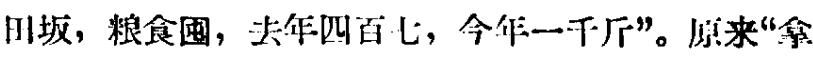

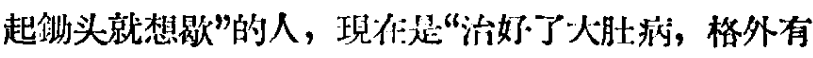

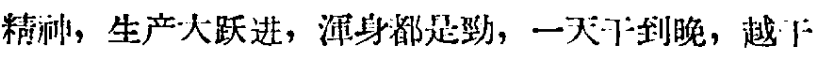
越有味”。西圾农紧利的楊家車村，連攸生产丰收，今

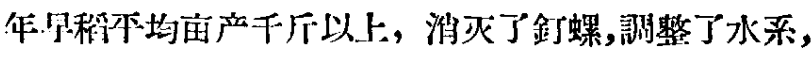

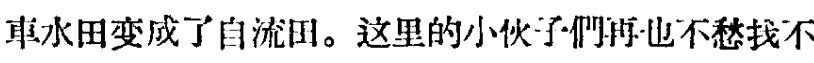

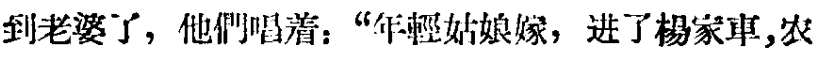

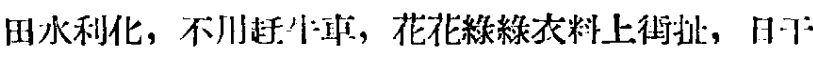

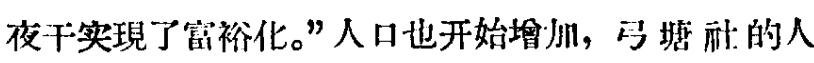
几，1957 年比 1956 作增加 20.6\%。整个牧区現了 人畜兴旺, 五谷丰登, 欣欣向荣的新气象。人們打心 底感激共产党, 感激毛主席, 說: “洺有共产党就洺 有今天”。

\section{血吸虫病的防治措施}

\section{一、健全組織，加强领导}

为了少强对血吸出病防治工作的创导, 1954 仵 行政.上成立了余汇县血吸虫病防治委員会, 1955 年 党中央提出限期消灭血吸虫病的号召以后, 党内成立 丁以县委青記为领导的县委血吸出病防治五人小組, 同时改选了行政上的血吸虫㿇防治委員会, 扩大了机

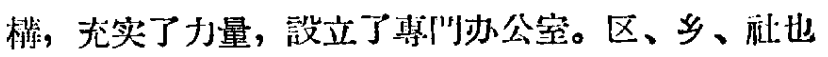
进一步健全了防洽領导机棈。从而做到了一級抓一 級, 一环扣一环。

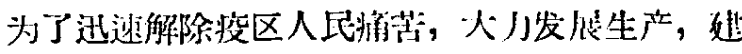

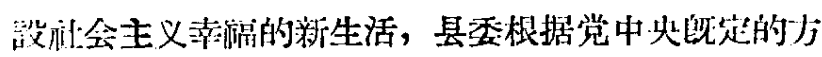
邻和措施, 及省、地委消灭血吸出病的規划䊑利, 䋨

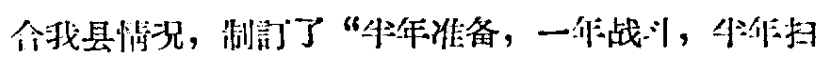
尾，网作消灭”的規划，捉法了“以生产为中心，血防方 
为重点”*的原勋,要求沙灭釘螺和兴修水利相結合,治

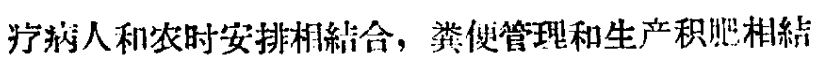

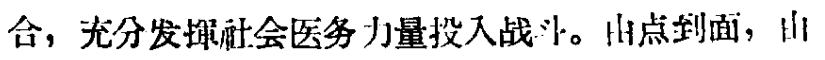
哭计到經常, 全面开度一系列政治运街。

\section{二、絬合水利, 結合生产, 大小开展灭蝶}

(1)“开新境旧”灭蝶: 这是我县灭蝶所尔取的主 妿方法。1955作以前,任馬南乡进行了小块“三光灭蝶”

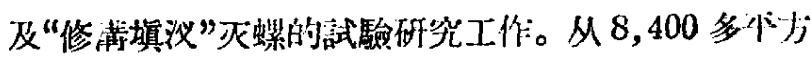
公人的灭螺成績来看, 好处是: 两种方法都可消灭一 定数量的崄蠌, 候点是“三光灭蝶”一网次不易彻底, 如技术指导不当, 叮以造成人为搬家現像。县委認监 总結了試驗性的灭蝶經驗, 認为上埋釷蝼是灭螺較为 理想的方法，适合我县釷蜗分佈为满渠型的特点。内 此, 决定采取这种方法灭蝶, 提什了“开新嫔旧, 消

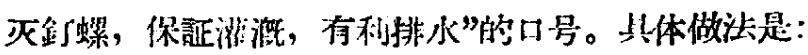

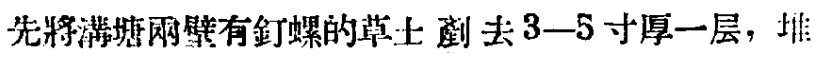

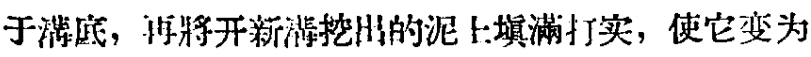

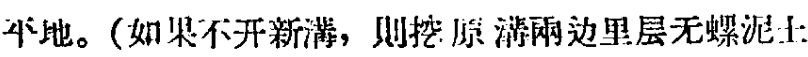

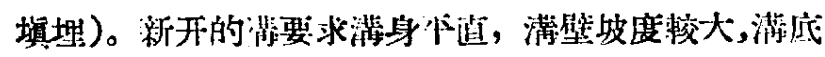

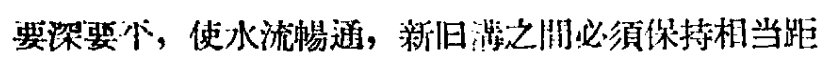
离, 任新旧交文之处要进行特殊处理。从 1955 年 10

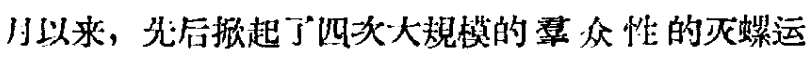

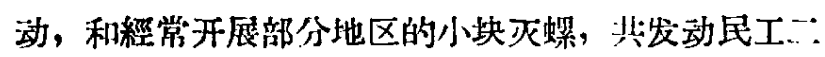

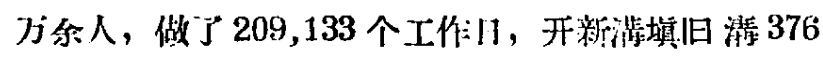
条, 全挔 397 华里, 填水塘 363 几, 灭蝶面积 417,351 冲方公人。根据多次进行的灭蛿效果覌察, 証明 “开

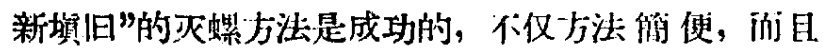
效果稳定彻位。齿作反复进行了细次檢查, 在 122

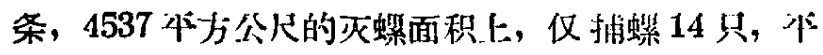
均媱渡为 $0.003 /$ 体方公及。今年五月文进行了一次全

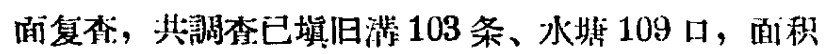

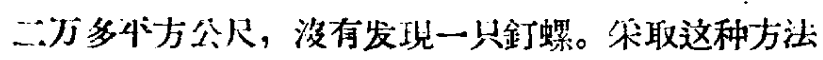

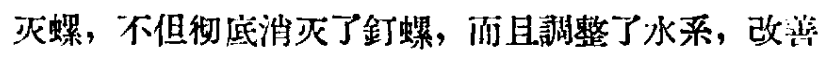
了”农田灌溉, 扩大了耕地面积。全县筷扩大耕地面积 532.2 甶, 車灌田变流灌田 1,500 亩, 光这兩項佔計 仅堆产橓谷 32 万余厅。

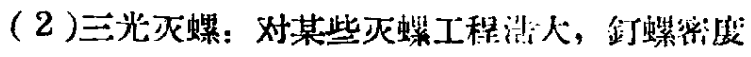

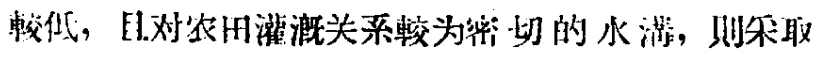

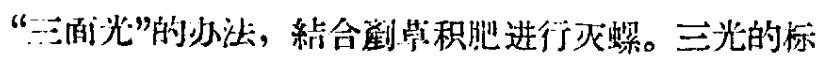

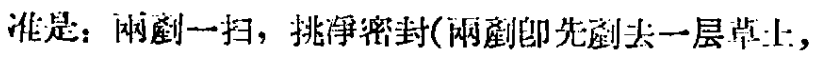

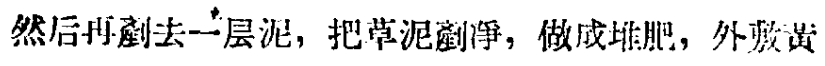

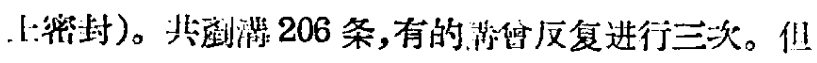
鉴, 这种方法灭蛿效果扑不彻底, 们蠌虽然大为減 少，但仍有少数漏网。如弓䛸乡檢查了“三光灭蝶”的

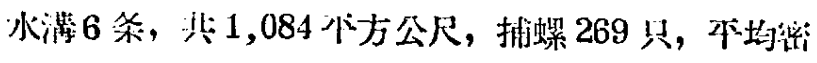
度还有 0.97 少/4方公尺。因此最后仍策用“开新填
旧”的方法, 对所有三光水檴进行灭螺补課, 才达到 了彻底消灭釷螺。

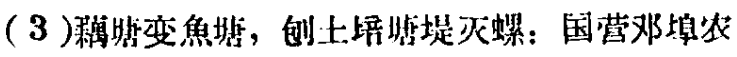
㘯存藕墌三口, 寄生着大量釷螺, 唋蝶密度最高达

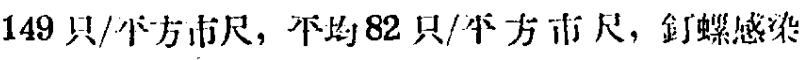
率为 $10.6 \%$ 。1957 年該坊采取这种方汒进行灭螺:

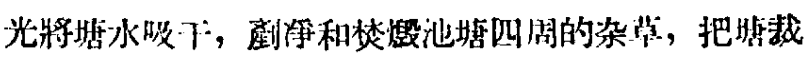

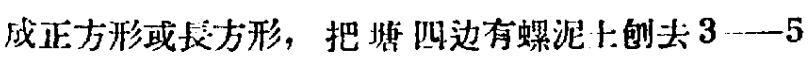

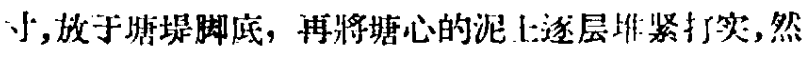

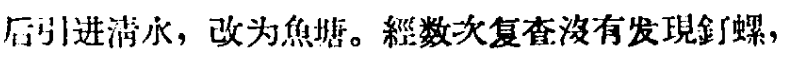
一次郎达圳百分之百的灭螺效桨。

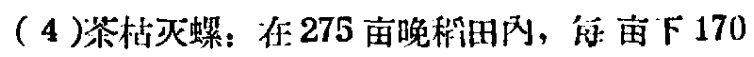
-.-220个染估, 只要灭蝶前掌握天气变化, 控制水

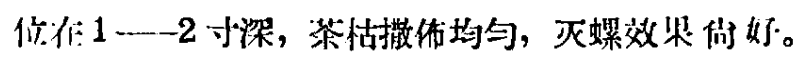

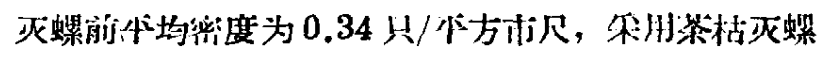

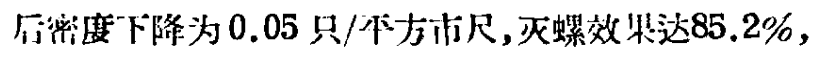
如能配合“三光灭螺”，効效果更佳。

三、結合农时, 合理安排治疗

烃据生产季节, 䋽合安排劳力, 分期分批进行治

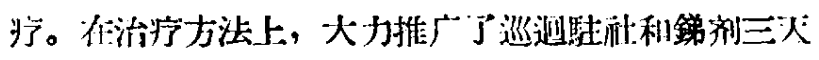

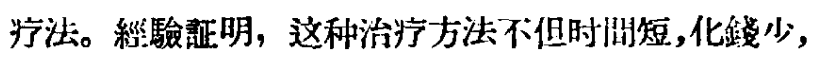
治将多，便利翠众，而日效紧良好。在全部收治的 4,392 人中死亡率仅为 $0.67 \%$ 。为了少强血防部刉和

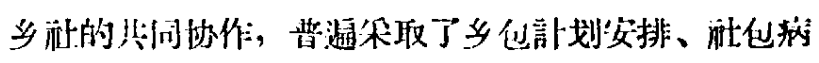

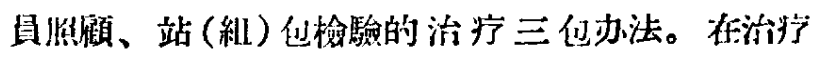

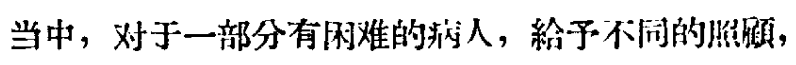
統一是在治疗前后活当分配輕活, 保取多做工分, 或附性减少一部分义务工分息担, 以弥补治将期减少

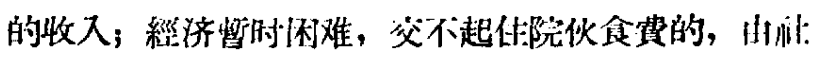

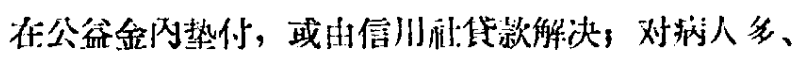

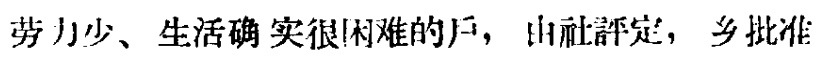
秴于”顺会救济。現在全县 4,042 个病人中, 除 17 个

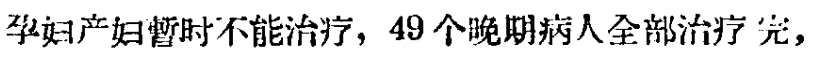

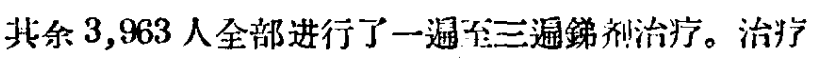
效紧, 本作5月份在比較严重的五个村尔用沉淀躬

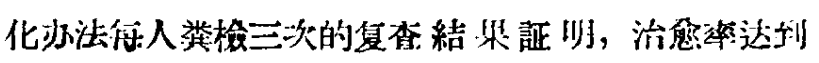
95.5\%。

叫、結合积肥，全消烡管:

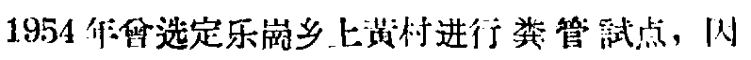

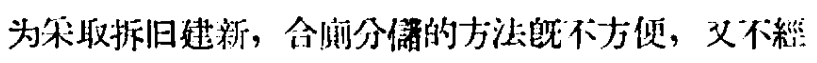
济, 票众不易接受。因此, 县委进行了僻究, 㮛据程

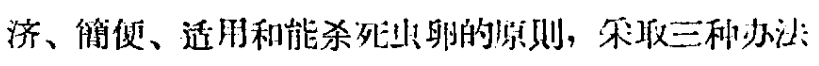

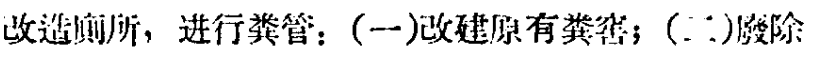

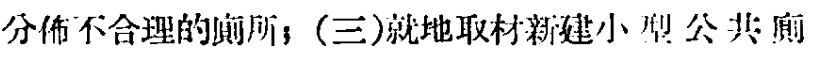

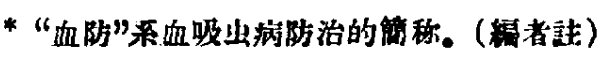




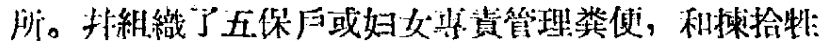

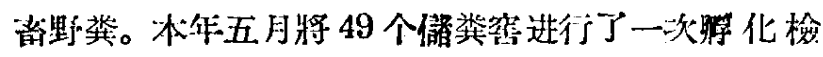
查, 絬果全部是阴性。

五、保护水源，防此新的感梁

方法是实行分悲使用，村村建访水非。現用水井，

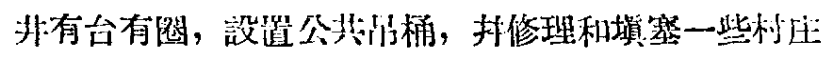
附近的水焎，从而倣到了人人使用安全水。

公、为该处理：已发現的 65 头耕牛，全部于五

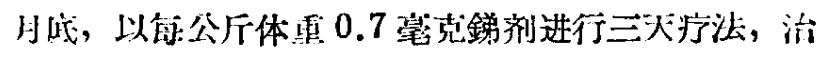
疗完策。

\section{几点体会}

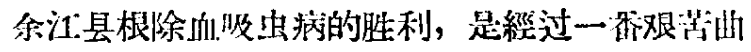
折的过程的。开初, 我們兓沟有成功的經驗可資借

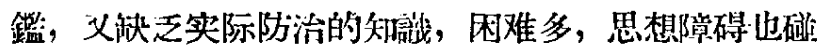
到不少。但我們認誐到党交給我們的重大責任, 深知

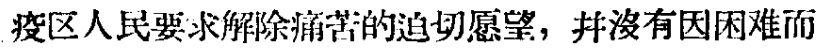
停止不前, 我們紧紧低靠着上級党委的正确领导, 低

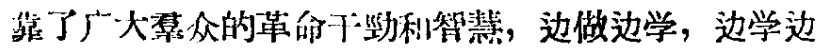
做, 从实践中摸索經驗, 克服网难, 丰富自己; 从失 敗中吸取教訓, 我任改进办法, 勇待直前的从一个胜 利走向另一个胜利。

几作来我們在和血吸虫疤的汗争:中，有以下几点 体会:

一、血防工作必須全党动手, 全力以迯, 层层创 导抓起来, 非动子能逢勃开展。

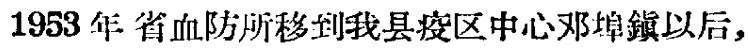
全县血防工作就开始了。当时县委对于血防工作与发 展生产、增进人民身体健康的关系是比較有認䇅的, 但对党的积极防治方敘的理解却不全面, 把积极的防j 治, 看成純粹医樂上的治疗, 把全党的一項重要工 作，看成是医疗部䅀的等。县委成員具体分工领导血 防工作也不明确, 組織机幥也不健全, 便血防工作形 成一般号留, 没有少体的佈署、要求和措施。在疫区 工作的于部, 主哭忙于抓互相合作、抓生产, 而对血 防工作则看作“与已无关”，不愿过問。血防工作人 員, 有工作热惊, 但缺少工作办法, 在进行工作中瞈

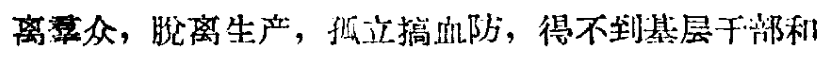

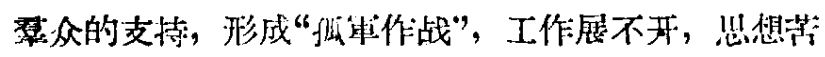
閶，信心不离，工作不够安心，闹时慗众受血吸热获 的折缕和威胁, 劳动无少, 做事无心, 生产也搞不 好。在这种衸况下，县委日谷觉祭到自己工作上的缺 点, 因此, 刜强了这方面的领导力量, 將血防工作们 人县委經常的議事日程, 同生产和其他各項重大工

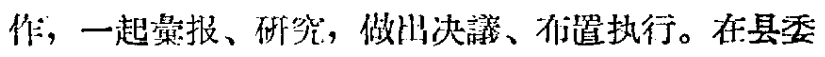
的集体㖽导下，白上而下的建立了組織机構，层层指 定了哲人斯误，县委五人小組出第一畫記担任組長，

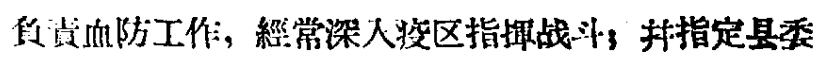

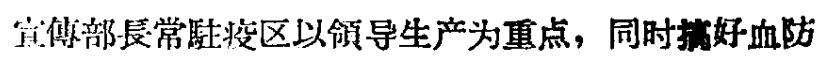
工作。为了指掫及时, 五人小組办公窒搬到疫区与血 防站合署办公。各没区、錤、乡、农㘯和农業酰地都 有暂記或副整記担任三人小組長，規定了具体任务。 此外, 县委每次召开会議佈置工作时, 血防工作总是 被列为重要任务之一提计来; 对于血防工作中的重大 問題都經县委或常委会符綸解决，有关血防工作的指 亦, 也由县委及时批轉下达。这样一来, 方向明确, 要求其体, 任务佈置及时, 韭記掛了收, 上了馬, 亲 自指揮作战, 党涹在血防工作上迅速形成了集体領导 核心, 血防工作再不是尌業人員孤軍作战, 而变为全 党全民的工作了。这时, 鄂多不安心血防工作的F 部, 也認識到解除人民痛苦的职責是光荣的, 少数開

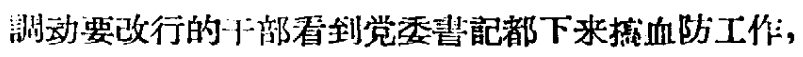
檢討了自己的錯兴思想, 端正了态度。县委接栔尔取

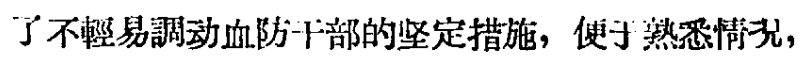
提出規律, 系統总絬經驗, 充实防治人具的本領,

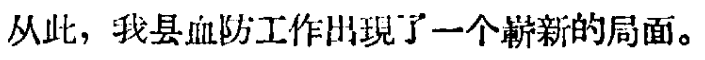

二、抓化政治思想工作，紧紧伐靠㻎众，是堣好血防工作的动力; 徭切結合生产是搞好血防工作的关 䠊。

血防工作是一个广泛性的翌众工作，它与翼众切 身利害休诚相关, 要做好这一工作, 首先就要发动和

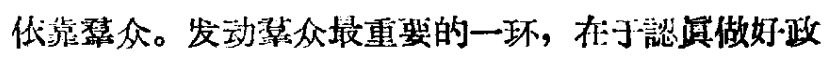

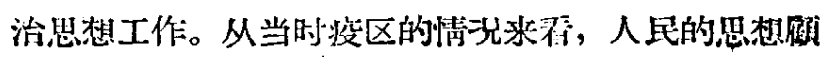
虑是很重的, 其中普遍琴法是不相信血吸出病能够治 好, 能够消灭。他們認为血吸出病在这里流行五十多

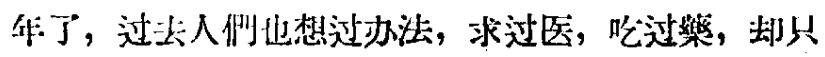

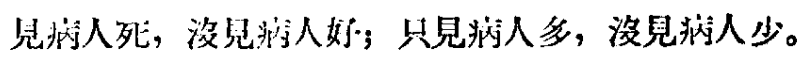
有些迷信思想严重的农民，根朴不相信釷螺是傳染血

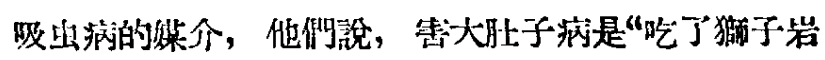
的水, 龙脈挖哚了, 地不发人, 命运不好, 生死由 天”。动員他們消灭釷螺, 他們說: “快到死的人了, 也該积点德，还忹去残等生灵”，他 强参加的人思想 開題未解决, 是应付干部, 效果不大; 給他們检查大 便了解病情就更不率是。不少乡社干部也和覃众一 样, 对根除血吸出病表現沟有信心, 他們認为县委訳!

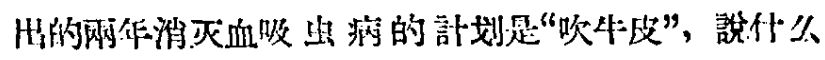
“反正是党的决定, 世做就做, 行不行誰知道”, “金厂 蜲又多又小，等消灭掉，人也死光丁”。在困难面前， 我們沟有灰心丧气，我們知道，椊众不积极投入血防， 扭不是对自己的生命、健康、生产、生活政不关心, 主要是疑虑沒有解除, 只要加强政治思想工作, 破除 他們的宿价迷信, 武裝以科学知裁, 他們就会从旧思

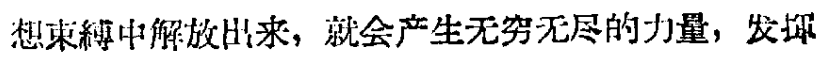


无穷的智慧。于是我們从上到下、从干部到草众，辟 开了广泛染入的宣傅动員工作，运用訴苦、对比、面涂

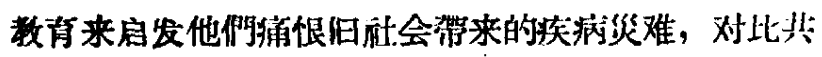
产党对他們的关怀, 坚定他們相信党的政策、措施, 用自己的力量, 創造新的生活。同时, 广洰逝俗䍀解 有关防洽血吸出获的知裁、办法和利学道理, 証明血 吸虫将能够消灭的可能性、艰巨性，鼓舞他們的热 情。利用展臨、黑柲报、大字报、开展大棓諭、大会 宣傅、小会漫談、个别訲伤談心等多种多样形式, 使

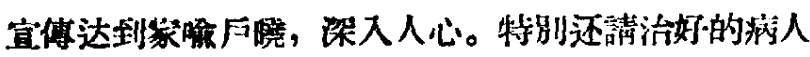

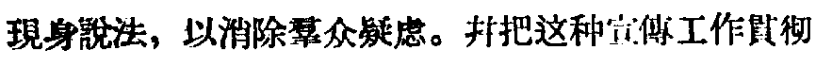
到每个运动、短个环节, 做到經常化。

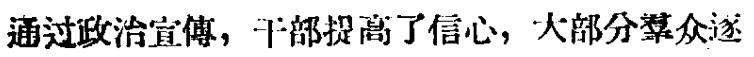

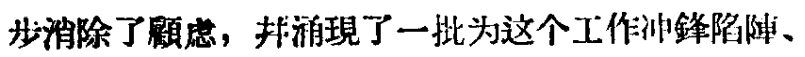

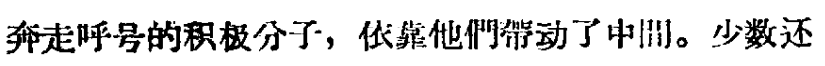
有怀影的人, 迫于形势, 也跟随进来, 不过, 当他例

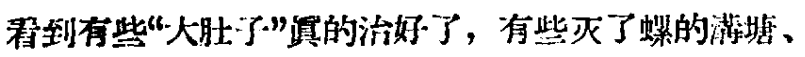

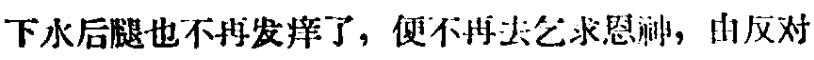
变为拥护, 变为自筧的行动了。

大規模血防工作一展开，跟着而来的是血䏚工作 如何和生产相結合的問題, 因为疫区劳动)少, 結合 不好, 就会䫏此失彼。开始, 在一部分下部中产生一

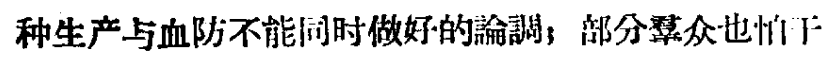

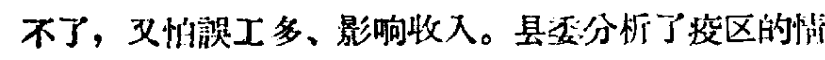
况, 証为只要有一个血防和农浆生产有机絬合的通盤 計划作指导, 兩种工作不但不会发生矛原, 而且会起 互相促进的作用。县委近过摆事实、满道理、算絒滞 的办法, 向干部和塹众提们了有打的涂据, 这就是根 据各个农时的特点，佈道不间的防治仕务，既有人涀 模地婴击性灭蝶运动，也有經常性小块灭絮工作。例 如冬季兴修水利、积吅，开废大规模灭蝶了，季节性的

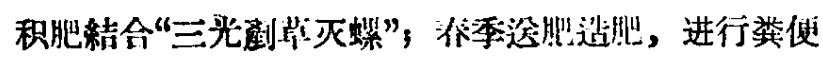

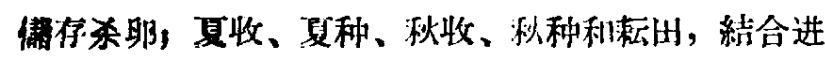
行田同灭螺和条卵。在治将上，农閒火量治㐌劳动 小，农忙治妇女、小捡和重患者，治㐨方法上，化整为

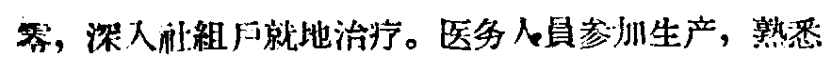
生产。千部、翠众看理这种办法能行，立郎分男把生 产你务、防洽工作、劳力多少，进行排队，訂出坛部

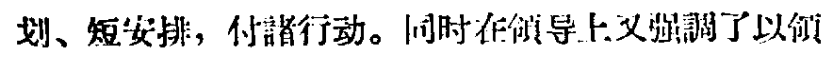
导生产的力法，来们导血防工作，普遥实行《 紌（維

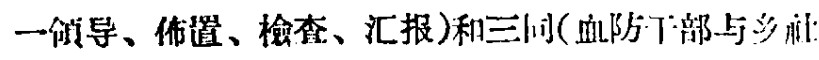

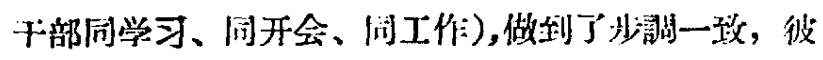
此歌成一体。这样做的絬果, 生产得到了全面发徒,

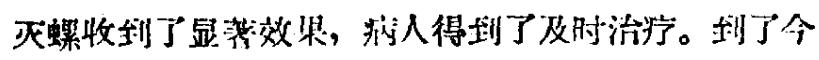

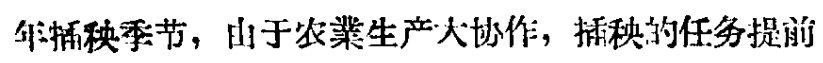
完成了，而百分之百有劳动力的患有世湖接㖟了治将，
从此, 根除了血吸虫病。怀疑生产不能結合血防, 血吸

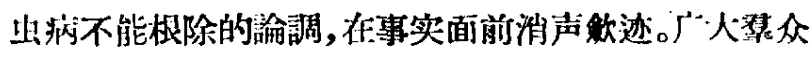

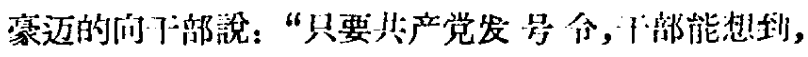

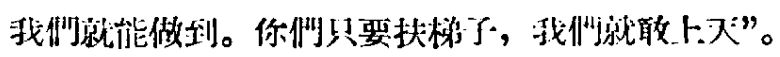

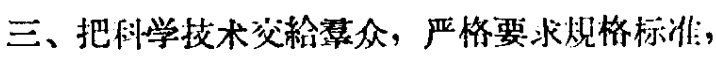
組織各部門大协作，随时注意解决工体间題，足巩洲 胜利、不断扩大战果的重要环节。

血吸出坊防方治工作是帶有很大找术州的工作，运

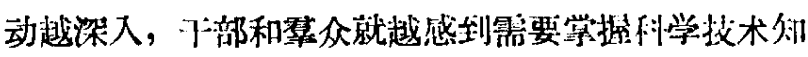
識。开始一个阶段，我們估这方面注意不够，部分灭 蝶工程做的不合标准规格, 有的灭蝶不彻位, 声车上

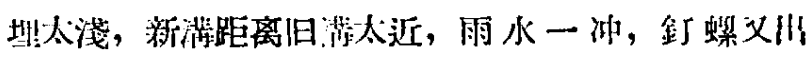
現。另外，水利部䍀和血防工作协作不够，有时灭蝃

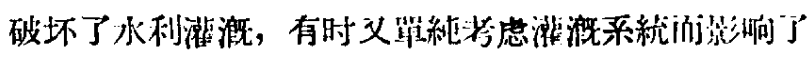

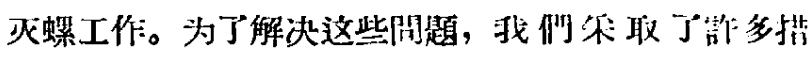

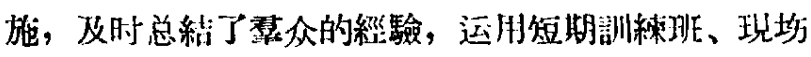

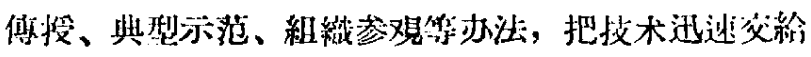

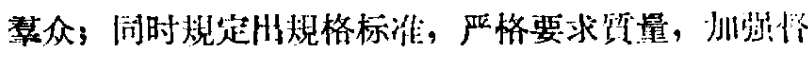

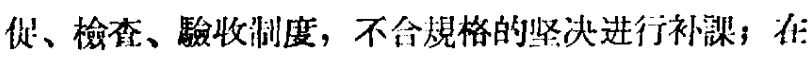
不影响資量、保証安全的前提下，佂治将上我們縒常

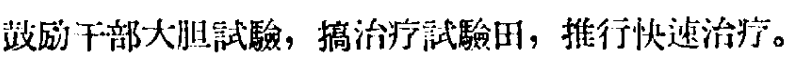

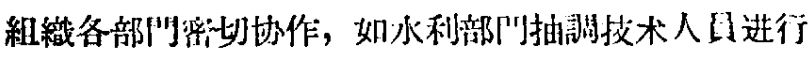

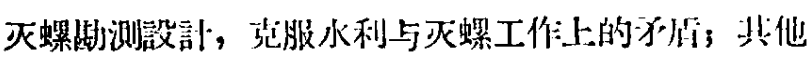

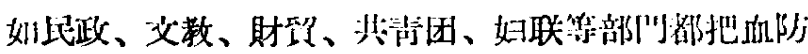
工作当成一項重要任务。对于血防的紧体间题, 如行

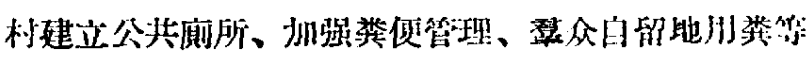
间題, 也都及时注意解决, 保踣了血防法动的全面此 常开展。

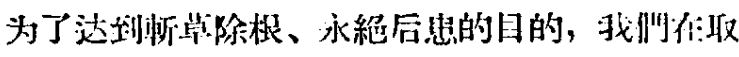

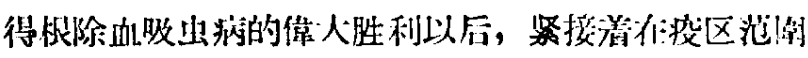

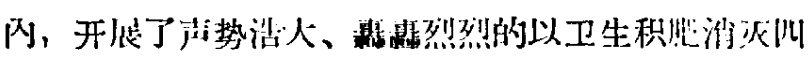
素为中心的巩估运动, 进一步败济了疫区环境卫生,

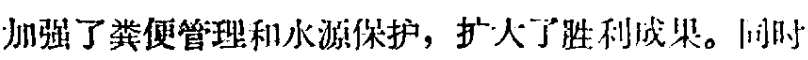

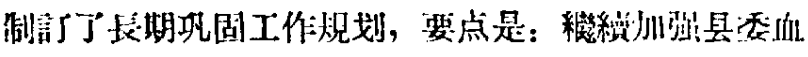

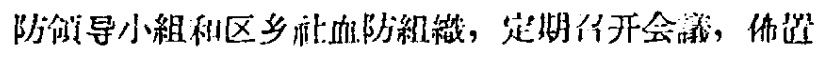

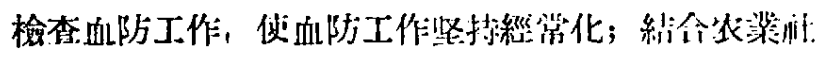

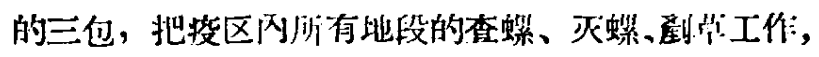

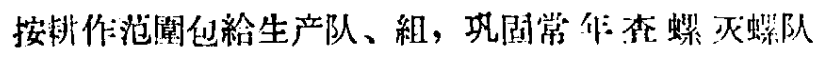

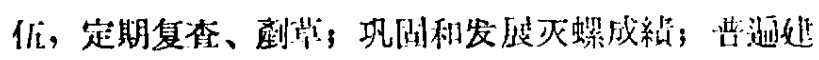

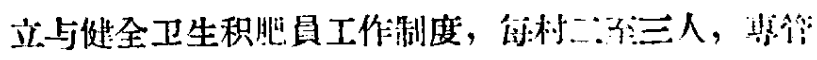

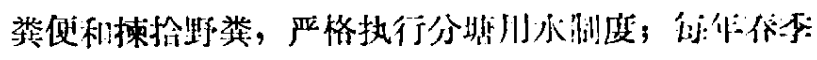

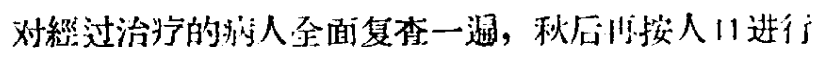

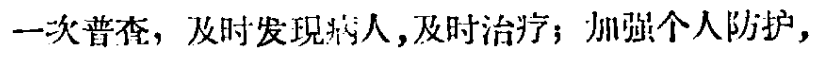

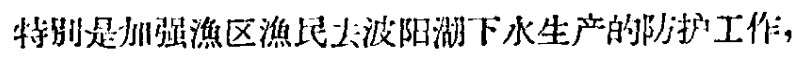

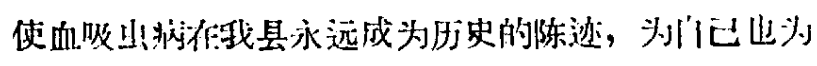
二丁孙万代造程。 